\title{
GSK3ß signaling is involved in ultraviolet B-induced activation of autophagy in epidermal cells
}

\author{
YANG YANG $^{1,2}$, HAIPING WANG ${ }^{1,3}$, SIYING WANG $^{1,4}$, MEI XU $^{1}$, MEI LIU $^{1}$, MINGJUN LIAO $^{1}$, \\ JACQUELINE A. FRANK ${ }^{1}$, SABAL ADHIKARI ${ }^{1}$, KIMBERLY A. BOWER ${ }^{1}$, \\ XIANGLIN SHI ${ }^{5}$, CUILING MA ${ }^{2}$ and JIA LUO ${ }^{1}$ \\ ${ }^{1}$ Department of Internal Medicine, University of Kentucky College of Medicine, Lexington, KY 40536, USA; \\ ${ }^{2}$ Department of Dermatology, Xijing Hospital, the Fourth Military Medical University, Shannxi, Xi'an 710032, P.R. China; \\ Departments of ${ }^{3}$ Neurobiology and ${ }^{4}$ Pathophysiology, School of Basic Medicine, Anhui Medical University, Hefei, \\ Anhui 230032, P.R. China; ${ }^{5}$ Graduate Center for Toxicology, University of Kentucky College of Medicine, \\ Lexington, KY 40536, USA
}

Received June 8, 2012; Accepted July 27, 2012

DOI: 10.3892/ijo.2012.1620

\begin{abstract}
Ultraviolet B (UVB) exposure causes damage to skin and represents the primary etiological agent for skin cancer formation. UVB induces DNA damage and apoptosis in epidermal cells. In this study, we demonstrated that UVB activated autophagy in JB6 epidermal cells, which was evident by the formation of LC3 puncta, the induction of LC3 lipidation, the increase in beclin 1 expression, and the decrease in the levels of p62. Autophagy appeared to be a protective response to UVB-induced damage because inhibition of autophagy exacerbated UVB-induced cell death, and stimulation of autophagy offered protection. Furthermore, we demonstrated that glycogen synthase kinase $3 \beta$ (GSK3 $\beta$ ) was involved in UVB-induced autophagy. UVB inhibited GSK $3 \beta$ activation by simultaneously enhancing phosphorylation at $\operatorname{Ser}^{9}$ and suppressing $\mathrm{Tyr}^{216}$ phosphorylation. GSK $3 \beta$ negatively regulated autophagy; overexpression of wild-type or S9A (constitutiveactive) GSK3 $\beta$ mutant inhibited UVB-mediated autophagy, while overexpression of a dominant-negative K85R mutant enhanced UVB-mediated autophagy. Inhibition of GSK3 $\beta$ also offered protection against UVB-mediated damage. UVB activated AMP-activated protein kinase (AMPK), an important regulator of autophagy through the inhibition of GSK3 $\beta$. Taken
\end{abstract}

Correspondence to: Professor Jia Luo, Department of Internal Medicine, University of Kentucky College of Medicine, 1095, Veterans Drive, Lexington, KY 40536, USA

E-mail: jialuo888@uky.edu

Dr Cuiling Ma, Department of Dermatology, Xijing Hospital, the Fourth Military Medical University, 15, Changlexi Road, Shannxi, Xi'an 710032, P.R. China

E-mail: macuiling@fmmu.edu.cn

Key words: apoptosis, carcinogenesis, protection, protein degradation, skin damage together, our results suggest that UVB-stimulated autophagy is a protective response for epidermal cells and is mediated by the GSK3//AMPK pathway.

\section{Introduction}

UV irradiation is a major environmental stressor that results in altered cutaneous functions: for example, induction of inflammation, dyspigmentation, premature aging, skin cancer, and attenuation of barrier function (1). The terrestrial solar UV spectrum can be divided into UVA (320-400 nm), UVB (280-320 nm), and UVC (200-280 nm). Wavelengths in the UVB region are absorbed into the epidermis of the skin and cause skin disorders such as the formation of sunburn cells (apoptotic cells) and skin cancer $(2,3)$.

UVB causes DNA damage and apoptosis of epidermal cells, and the signaling pathways associated with UVB-induced cell death have been extensively investigated (3). However, the cellular self-protection system in which epidermal cells respond to UVB is unclear. Autophagy is an intracellular degrading and recycling process by which organelles, cytoplasmic components, and invading pathogens are delivered to lysosomes for degradation (4,5). This process recycles cellular components and produces building blocks under stress conditions/nutrient starvation; it also eliminates damaged proteins/organelles (4-6). Therefore, autophagy has been proposed to be a cellular self-protection process in response to stress conditions $(7,8)$. However, some studies suggest that autophagy may contribute to cellular damage (7).

In this study, we examined the effect of UVB on autophagy in a mouse epidermal cell line (JB6). JB6 cells have been extensively used to study the mechanisms of epidermal cell transformation (9-11). UVB causes the death of JB6 cells in the form of apoptosis (12). We demonstrated that UVB activated autophagy in JB6 cells, and autophagy appeared to be a protective response to UVB-induced damage. Furthermore, we showed that GSK3 $\beta$ negatively regulated autophagy and inhibition of GSK $3 \beta$ also offered protection against UVB-induced cell death. 


\section{Materials and methods}

Materials. LiCl, bafilomycin A1, wortmannin, rapamycin, 3-methyladenine (3-MA) and anti-actin antibody were purchased from Sigma (St. Louis, MO, USA). Anti-beclin 1 antibody was purchased from Abcam (Cambridge, MA, USA). Anti-LC3 antibody was purchased from Medical and Biological Laboratories (Nagoya, Japan). The antibodies directed against GSK3 $\beta$, phospho-GSK3 $\beta$, AMPK, phospho-AMPK and p62 were obtained from Cell Signaling Technology (Beverly, MA, USA).

Cell culture and UVB irradiation. JB6 mouse epidermal cells (CI 41) were cultured in EMEM supplemented with $10 \%$ fetal bovine serum (FBS), $2 \mathrm{mM} \mathrm{L}$-glutamine, $25 \mu \mathrm{g} / \mathrm{ml}$ gentamicin, $100 \mathrm{U} / \mathrm{ml}$ penicillin and $100 \mu \mathrm{g} / \mathrm{ml}$ streptomycin at $37^{\circ} \mathrm{C}$ with $5 \% \mathrm{CO}_{2}$. The establishment of JB6 cell lines stably expressing wild-type GSK3 $\beta$ (WT), constitutively active GSK3 $\beta$ (S9A), and dominant-negative GSK3 $\beta$ (K85R) have been previously described (10). The cells were irradiated with a UVB lamp (UVP, $0-400 \mathrm{~mJ} / \mathrm{cm}^{2}$ ) as previously described (13) and then incubated at $37^{\circ} \mathrm{C}$ for the indicated time.

Detection of LC3 puncta. GFP-LC3 plasmid was a generous gift from Dr Gutterman (University of Texas MD Anderson Cancer Center, Houston, TX). Transfections were performed using Lipofectamine ${ }^{\mathrm{TM}} 2000$ (Invitrogen, Carlsbad, CA, USA) according to the manufacturer's protocol. At $24 \mathrm{~h}$ after transfection, cells were exposed to UVB irradiation and were examined by a fluorescence microscope at indicated times. The GFP-LC3 puncta/cell were quantified as previously described $(14,15)$. For each group, twenty cells in randomly selected visual fields were counted. The experiment was replicated three times.

Determination of cell viability. Cells were exposed to UVB irradiation at indicated dosages and incubated for $24 \mathrm{~h}$. Cell viability was determined by MTT assay as previously described (16).

Immunoblotting. The procedure for immunoblotting has been previously described (10). Briefly, cells were washed twice with PBS and lysed with RIPA buffer [150 $\mathrm{mM} \mathrm{NaCl}, 0.1 \%$ sodium dodecyl sulfate (SDS), $50 \mathrm{mM}$ Tris ( $\mathrm{pH} 8.0$ ), $0.5 \%$ deoxycholic acid sodium, $1 \%$ Nonidet P-40 (NP-40), $0.1 \mathrm{mg} / \mathrm{ml}$ phenylmethylsulfonyl fluoride, $3 \%$ aprotinin, and $1 \mathrm{mM}$ sodium orthovanadate] on ice for $10 \mathrm{~min}$. Cell lysates were centrifuged at $12,000 \mathrm{rpm}$ at $4^{\circ} \mathrm{C}$ for $10 \mathrm{~min}$. The supernatant was then collected and the protein concentration was measured with a protein assay kit (Bio-Rad Laboratories, Hercules, CA, USA). An aliquot of the total protein $(40 \mu \mathrm{g})$ was loaded into each lane of an SDS-polyacrylamide gel. The protein was electrophoretically transferred to nitrocellulose membranes and blocked with 5\% BSA in $0.01 \mathrm{M}$ TBS (pH 7.4) and $0.05 \%$ Tween-20 (TBST) at room temperature for $1 \mathrm{~h}$. The blots were probed with primary antibodies for $2 \mathrm{~h}$ at room temperature or overnight at $4^{\circ} \mathrm{C}$. After three quick washes with TBST, the membranes were incubated with horseradish peroxidase-conjugated goat anti-rabbit or goat anti-mouse IgG (Amersham, Arlington Heights, IL, USA) for $1 \mathrm{~h}$ and the bands were visualized with the enhanced chemiluminescence method (Amersham).
Statistical analysis. All the data are expressed as the mean \pm SD from at least three independent experiments. The statistical analysis was performed using the analysis of variance (ANOVA) followed by post hoc analyses. A value of $\mathrm{p}<0.05$ was considered statistically significant.

\section{Results}

UVB irradiation activates autophagy. First, we examined the effect of UVB irradiation on autophagy in cultured JB6 mouse epidermal cells. The synthesis and conversion of LC 3 is connected closely with the level of autophagy, making it a key marker in cells (17). The formation of LC3 puncta is an important indication of autophagy. We transfected JB6 cells with a GFP-LC3 plasmid, then examined the distribution and amount of green fluorescence LC3 puncta. We determined the effect of UVB irradiation at 0 , $25,100,400 \mathrm{~mJ} / \mathrm{cm}^{2}$ after $24 \mathrm{~h}$ of exposure. As shown in Fig. 1, a significant increase of LC3-GFP puncta formation was observed after UVB exposure at $100 \mathrm{~mJ} / \mathrm{cm}^{2}$. UVB irradiation at 25 or $400 \mathrm{~mJ} / \mathrm{cm}^{2}$ did not alter LC3 puncta. LC3 lipidation, which is indicated by the formation of LC3-II, is an index of autophagy. We demonstrated that UVB irradiation $\left(100 \mathrm{~mJ} / \mathrm{cm}^{2}\right)$ increased the level of LC3-II (induction of LC3 lipidation) in JB6 cells in a time-dependent manner (Fig. 1C). Meanwhile, the expression of beclin 1 was upregulated, but the level of $\mathrm{p} 62$ was downregulated (Fig. 1C). Beclin 1, also known as Atg6, is a protein required for the formation of the initial autophagic structure, while p62 is regulated by autophagy-dependent degradation. Together, these results suggested that UVB irradiation activated autophagy.

We next sought to determine the role of autophagy in UVB irradiation-induced cell death. As shown in Fig. 2, activation of autophagy by rapamycin offered protection, whereas inhibition of autophagy by bafilomycin A1, wortmannin, or 3-MA exacerbated UVB irradiation-induced cell death. These results suggested that autophagy was a protective response to UVB irradiation-induced damage.

The involvement of GSK3 $\beta$ in UVB-activated autophagy. The activity of GSK $3 \beta$ is negatively regulated by the phosphorylation at $\mathrm{Ser}^{9}$, but positively at $\mathrm{Tyr}^{216}$ (18). We showed that UVB irradiation increased the level of pGSK3 $\beta\left(\operatorname{Ser}^{9}\right)$ and decreased pGSK3 $\beta\left(\right.$ Tyr $\left.^{216}\right)$, indicating it inhibited GSK3 $\beta$ activity (Fig. 1C). To evaluate the role of GSK3 $\beta$ in UVB-induced autophagy, we established JB6 cells stably expressing various GSK3 $\beta$ mutants. These constructs included wild-type (WT), constitutive-active (S9A) and dominant-negative (K85R) GSK33. S9A mutant is resistant to inhibitory regulation by restraining phosphorylation at $\mathrm{Ser}^{9} ; \mathrm{K} 85 \mathrm{R}$ mutant represents a deficit kinase and functions as a dominant-negative protein. We have previously shown they effectively stimulated or inhibited GSK3 $\beta$ activity, respectively (10). Overexpression of these exogenous GSK3 $\beta$ proteins was verified by the expression of a V5 tag by immunoblotting (Fig. 3A). We demonstrated that manipulation of GSK $3 \beta$ activity altered UVB-mediated autophagy. Upon UVB exposure $\left(100 \mathrm{~mJ} / \mathrm{cm}^{2}\right)$, overexpression of WT and S9A GSK3 $\beta$ significantly decreased the number of LC3 puncta, whereas K85R GSK3 $\beta$ increased the amount of LC3 puncta (Fig. 3B). Consistent with this result, overexpression of WT and S9A GSK3 $\beta$ decreased the level of LC3-II and beclin 1; overexpression of K85R increased the expression of LC3-II and beclin 1. Together, these data 
A

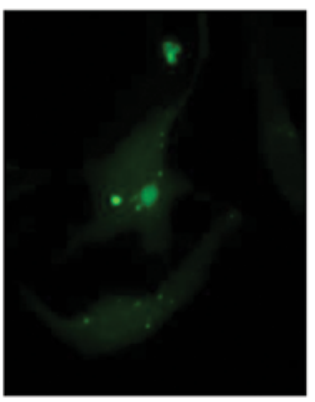

$0 \mathrm{~mJ} / \mathrm{cm}^{2}$

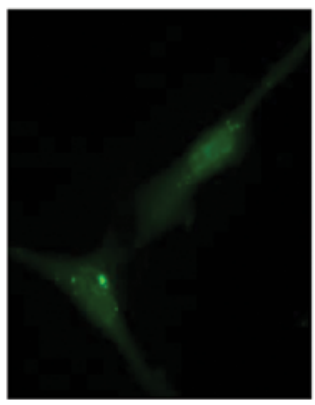

$25 \mathrm{~mJ} / \mathrm{cm}^{2}$

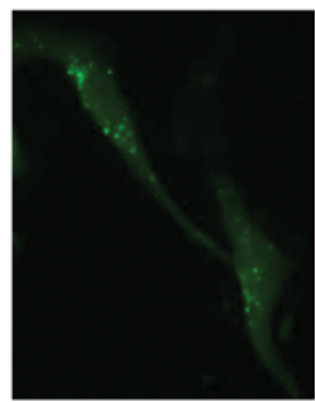

$100 \mathrm{~mJ} / \mathrm{cm}^{2}$

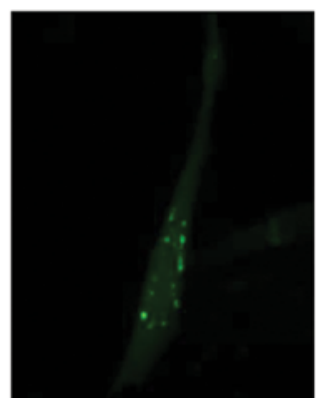

$400 \mathrm{~mJ} / \mathrm{cm}^{2}$

B

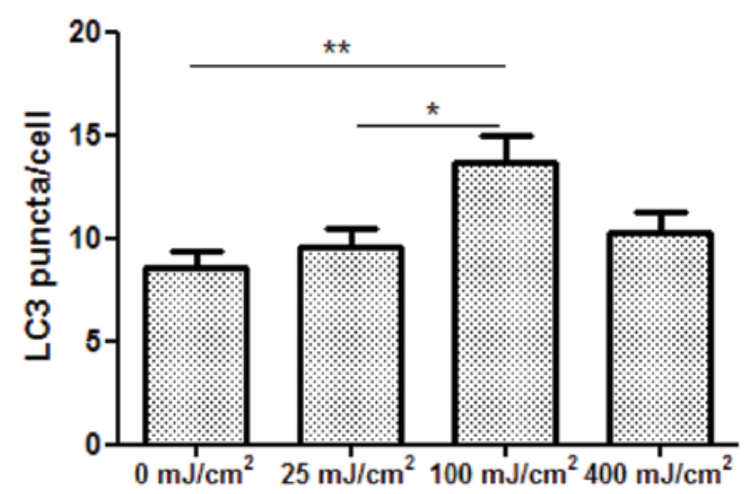

C

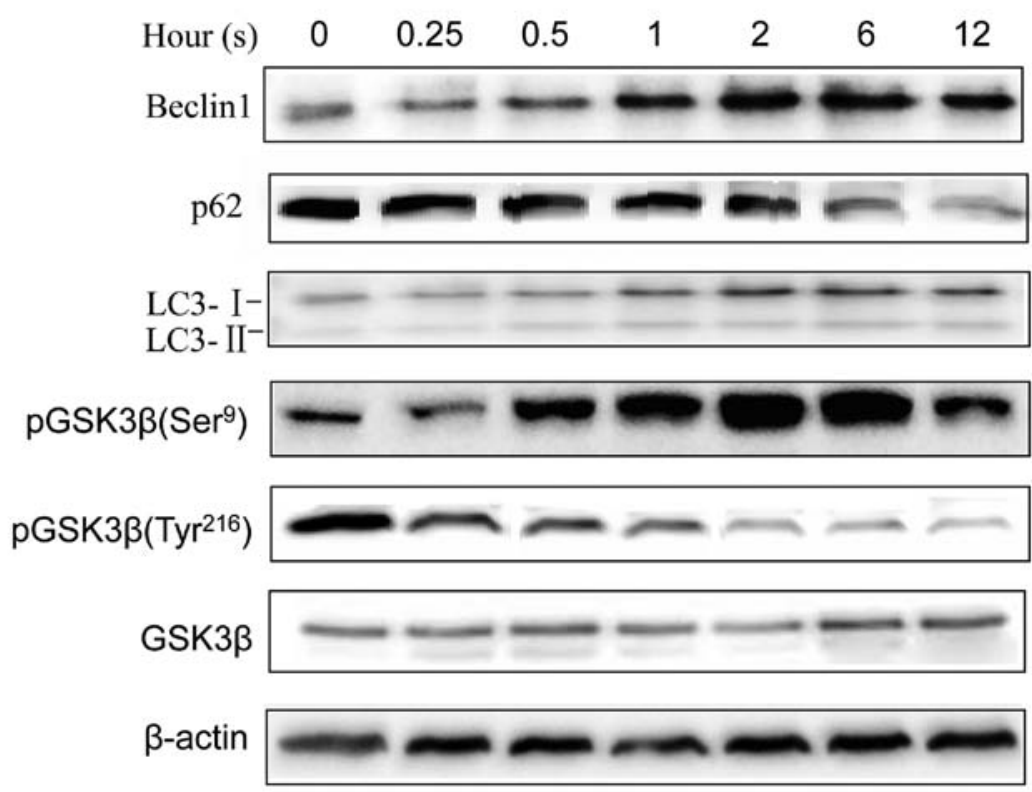

Figure 1. Effect of UVB on autophagy in JB6 cells. (A) JB6 cells were transfected with a GFP-LC3 plasmid and exposed to UVB irradiation $\left(25 \mathrm{~mJ} / \mathrm{cm}^{2}, 100 \mathrm{~mJ} / \mathrm{cm}^{2}\right.$, or $400 \mathrm{~mJ} / \mathrm{cm}^{2}$ ). The formation of GFP-LC3 punctate dots was visualized by a fluorescent microscope after incubation for $6 \mathrm{~h}$. (B) The number of GFP-LC3 puncta/cell was quantified as described under the Materials and methods. The experiment was replicated three times. ${ }^{*}$ and ${ }^{* *}$ denote statistically significant from the control group ( $\left.{ }^{*} \mathrm{p}<0.05 ;{ }^{* *} \mathrm{p}<0.01\right)$. (C) JB6 cells were exposed to UVB $\left(100 \mathrm{~mJ} / \mathrm{cm}^{2}\right)$ irradiation at specified times. The expression of p62, beclin 1, LC3 (LC3-I and LC3-II), GSK3 $\beta$, and phosphorylated GSK3 $\beta\left(\operatorname{Ser}^{9}\right.$ and $\left.\mathrm{Tyr}^{216}\right)$ was detected with immunoblotting. The expression of actin served as a loading control. The experiment was replicated three times. 


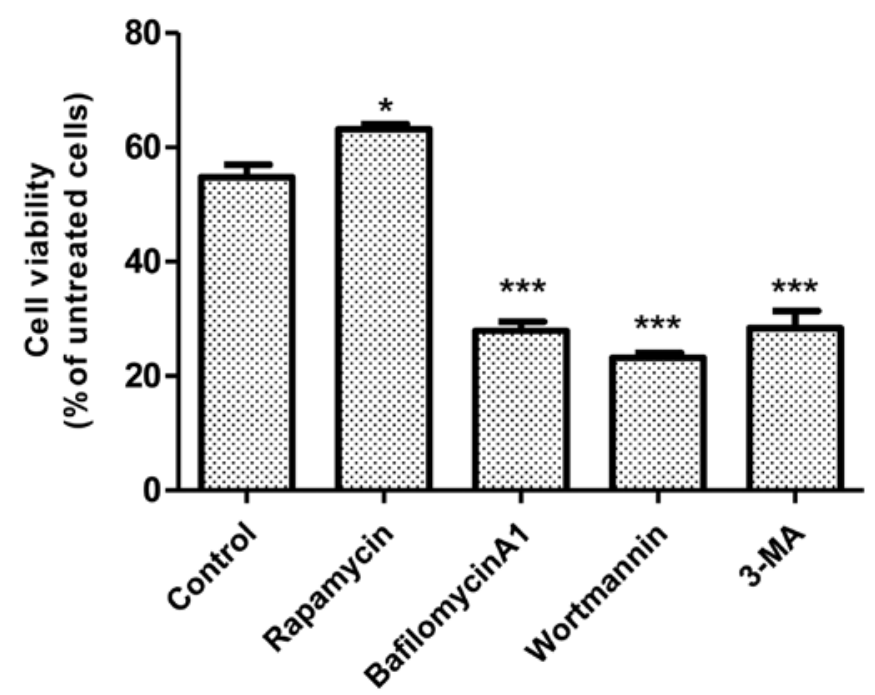

Figure 2. Effect of modulation of autophagy on UVB-induced cell death. JB6 cells were pretreated with rapamycin $(10 \mathrm{nM})$, bafilomycin A1 $(10 \mathrm{nM})$, wortmannin $(10 \mu \mathrm{M})$, or 3-MA $(5 \mathrm{mM})$ for $2 \mathrm{~h}$ and then irradiated by UVB $\left(100 \mathrm{~mJ} / \mathrm{cm}^{2}\right)$. After $24-\mathrm{h}$ incubation at $37^{\circ} \mathrm{C}$, cell viability was determined by MTT assay as described under the Materials and methods. The experiment was replicated three times. ${ }^{*}$ and ${ }^{* * * *}$ denote statistically significant from the control group $\left({ }^{*} \mathrm{p}<0.05 ;{ }^{* * *} \mathrm{p}<0.001\right)$.

suggested that inhibition of GSK $3 \beta$ resulted in an increase in autophagy. In parallel, overexpression of WT and S9A GSK3 $\beta$ exacerbated UVB-induced cell death, whereas overexpression of K85R GSK3 $\beta$ protected cells against UVB-induced cell death
(Fig. 4). Protection mediated by the inhibition of GSK3 $\beta$ was further supported by a study using lithium treatment. Lithium, an inhibitor of GSK3 $\beta$, reduced UVB-mediated cell death (Fig. 4).

Interaction between $A M P K$ and GSK3 $\beta$ in response to UVB. AMPK is a critical regulator of autophagy and activation of AMPK results in enhanced autophagy (19). We confirmed that UVB induced the phosphorylation of AMPK $\left(\mathrm{Thr}^{172}\right)$ in JB6 cells (Fig. 5). We further investigated the relationship between AMPK and GSK3 $\beta$. Inhibition of GSK3 $\beta$ by lithium was sufficient to activate AMPK (Fig. 6A). Furthermore, overexpression of dominant-negative K85R GSK3 $\beta$ enhanced UVB-stimulated phosphorylation of AMPK (pAMPK), whereas overexpression of S9A or WT GSK3 $\beta$ inhibited UVB-mediated pAMPK (Fig. 6B). These results suggested that GSK3 $\beta$ negatively regulated AMPK phosphorylation.

\section{Discussion}

In this study, we demonstrate for the first time that UVB can activate autophagy in epidermal cells, and autophagy appears to be a cytoprotective response to UVB-mediated damage.

UVB irradiation causes DNA damage and apoptosis of epidermal cells, contributing to human skin cancer in the process of tumor initiator and promoter (20,21). Mouse JB6 cells are a well-established in vitro model to study UVB-mediated damage and transformation of epidermal cells (22-24). Using this model, we demonstrate that UVB-induced reduction in the viability of JB6 cells is accompanied by the increase of autophagy which is evident by the formation of LC3 puncta, induction of LC3 lipidation, increase in beclin 1 expression, and decrease in the level

A

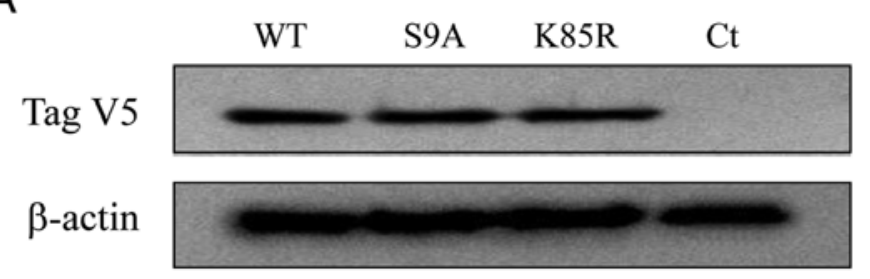

B

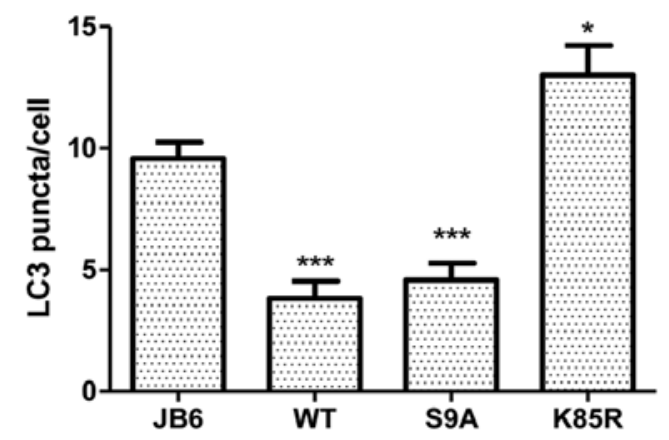

C

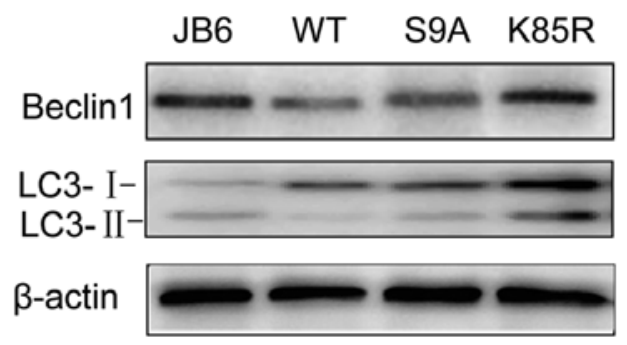

Figure 3. Effect of UVB on autophagy in JB6 cells stably expressing GSK3 $\beta$ mutants. (A) The expression of wild-type (WT), S9A and K85R GSK3 $\beta$ in JB6 cells was confirmed by the expression of a V5 tag by immunoblotting. (B) JB6 cells stably expressing WT, S9A, and K85R GSK3 $\beta$ were transfected with a GFP-LC3 plasmid for $24 \mathrm{~h}$. After that, cells were treated with UVB irradiation $\left(100 \mathrm{~mJ} / \mathrm{cm}^{2}\right)$ and incubated for $6 \mathrm{~h}$. The number of GFP-LC3 puncta/cell was quantified as described above. The experiment was replicated three times. ${ }^{*}$ and ${ }^{* * * *}$ denote statistically significant from the control group $\left({ }^{*} \mathrm{p}<0.05 ;{ }^{* * *} \mathrm{p}<0.001\right)$. (C) JB6 cells stably expressing wild-type, S9A, and K85R GSK3 $\beta$ were exposed to UVB irradiation $\left(100 \mathrm{~mJ} / \mathrm{cm}^{2}\right)$, and cell lysates were collected after $6 \mathrm{~h}$ of incubation. The levels of LC3 and beclin 1 were analyzed by immunoblotting. The expression of actin served as a loading control. The experiment was replicated three times. 


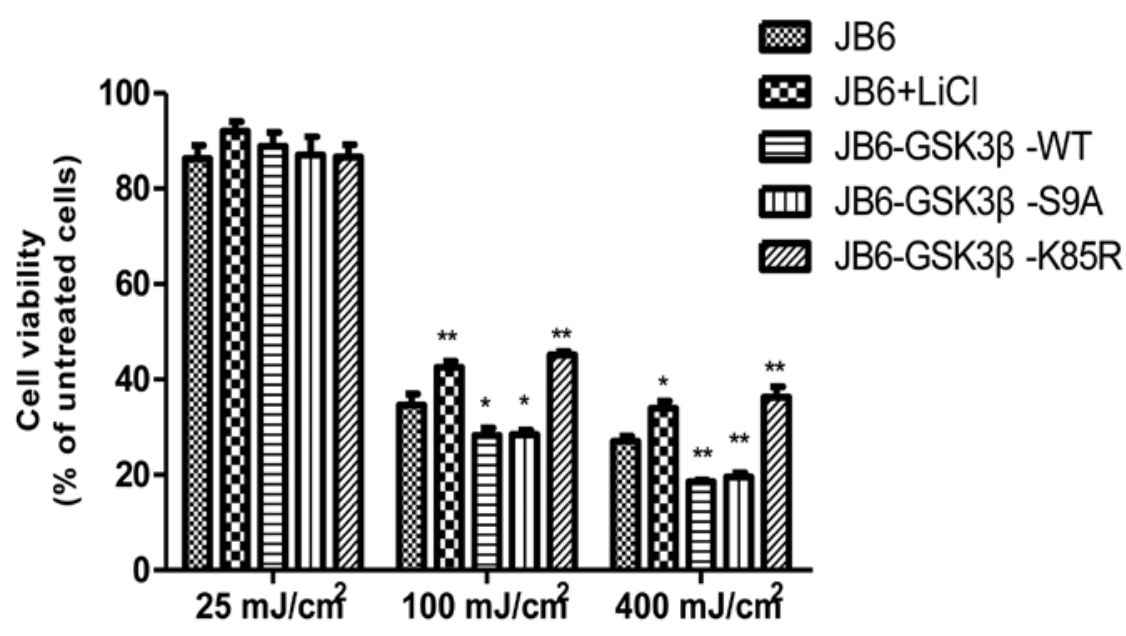

Figure 4. Effect of UVB on the viability of JB6 cells expressing GSK3 $\beta$ mutants. JB6 cells stably expressing WT, S9A and K85R GSK3 $\beta$ were exposed to UVB irradiation $\left(25 \mathrm{~mJ} / \mathrm{cm}^{2}, 100 \mathrm{~mJ} / \mathrm{cm}^{2}\right.$, or $\left.400 \mathrm{~mJ} / \mathrm{cm}^{2}\right)$. In some groups, JB6 cells were pretreated with $\mathrm{LiCl}(20 \mathrm{mM})$ for $1 \mathrm{~h}$ and then received UVB irradiation. After $24 \mathrm{~h}$, cell viability was determined by MTT assay as described under the Materials and methods. The experiment was replicated three times. * and ${ }^{* *}$ denote statistically significant from the control group ( $\mathrm{p}<0.05$ and $\left.{ }^{* *} \mathrm{p}<0.01\right)$.

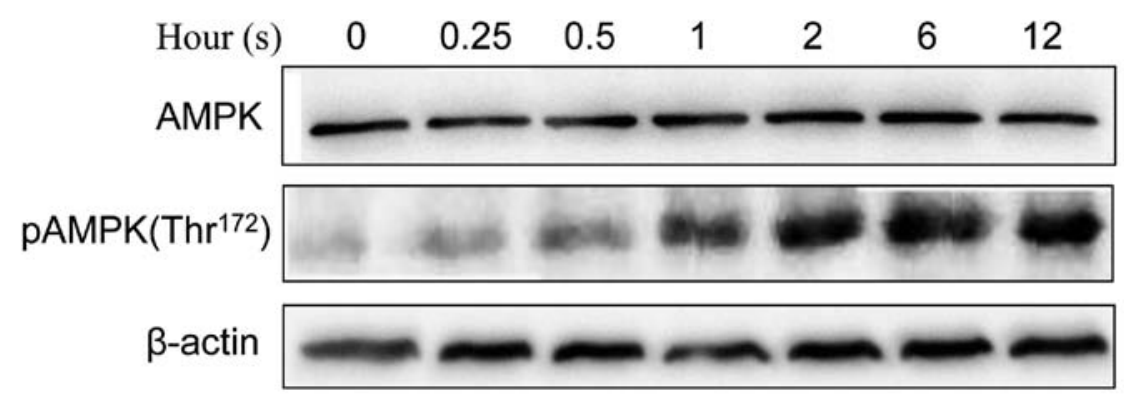

Figure 5. Effect of UVB on AMPK phosphorylation. JB6 cells were treated with UVB irradiation $\left(100 \mathrm{~mJ} / \mathrm{cm}^{2}\right)$. The protein samples were collected at specified times. The expression of AMPK and phosphorylated AMPK ( $\mathrm{Thr}^{172}$ ) was determined by immunblotting. The expression of actin served as a loading control. The experiment was replicated three times.

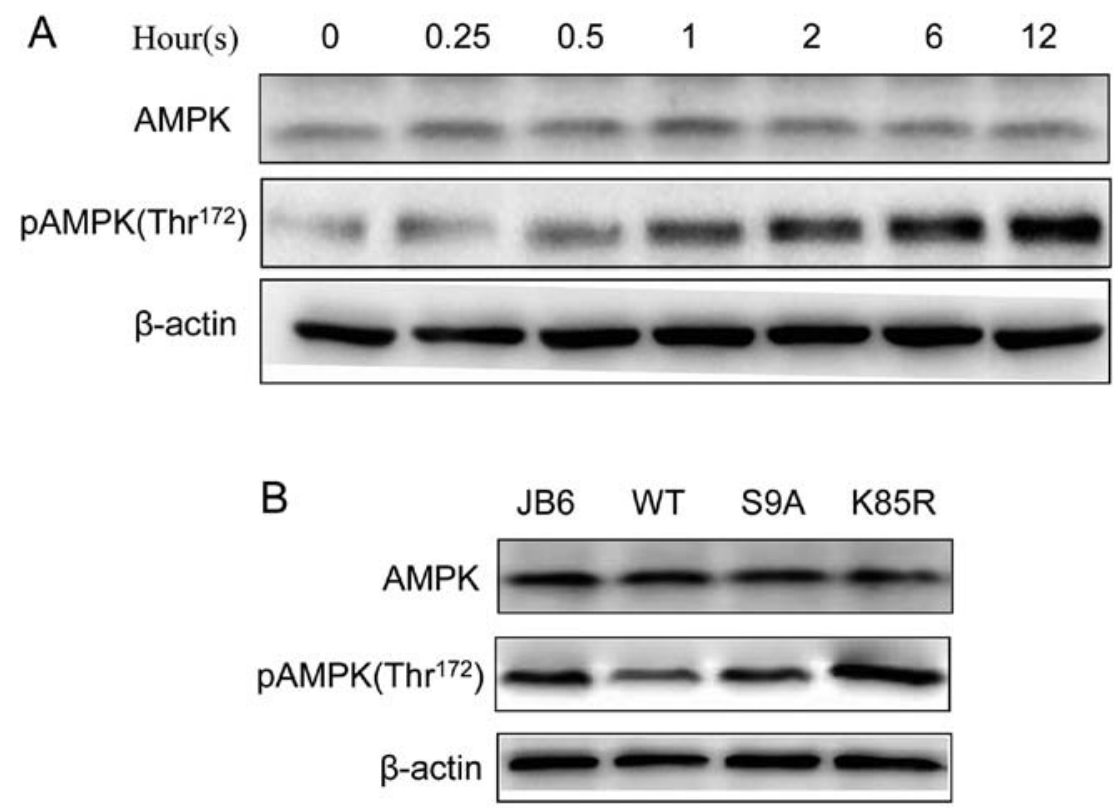

Figure 6. Role of GSK3 3 in UVB-mediated activation of AMPK. (A) JB6 cells were pretreated with $\mathrm{LiCl}(20 \mathrm{mM})$ for specified times. The expression of AMPK and pAMPK $\left(\mathrm{Th}^{172}\right)$ was examined with immunoblotting. The expression of actin served as a loading control. The experiment was replicated three times. (B) JB6 cells stably expressing wild-type, S9A and K85R GSK3 $\beta$ were exposed to UVB irradiation $\left(100 \mathrm{~mJ} / \mathrm{cm}^{2}\right)$ and incubated for $6 \mathrm{~h}$. The expression of AMPK and pAMPK $\left(\mathrm{Thr}^{172}\right)$ was examined with immunoblotting. The expression of actin served as a loading control. The experiment was replicated three times. 
of p62. Inhibition of autophagy by bafilomycin A1, wortmannin, or 3-MA exacerbates UVB-induced cell death. In contrast, activation of autophagy by rapamycin protects JB6 cells against UVB-mediated damage. This finding is consistent with a previous study showing that UV irradiation induced autophagy in A549 and H1299 cells $(25,26)$. In that study, autophagy also seemed to be cytoprotective, and inhibition of autophagy exacerbated UV-triggered apoptotic cell death in these cells (26). Similarly, autophagy was shown to be cytoprotective against apoptosis induced by DNA-damaging agents (25).

It is interesting to note that UVB induces autophagy in a dosedependent manner. At a low dosage, such as $25 \mathrm{~mJ} / \mathrm{cm}^{2}$, UVB does not affect cell viability and autophagy. At $100 \mathrm{~mJ} / \mathrm{cm}^{2}$, it causes cell death and activates autophagy. However, at a higher dosage, $400 \mathrm{~mJ} / \mathrm{cm}^{2}$, it produces more cell death, but fails to activate autophagy (Fig. 1). It is likely that at a high dosage, UVB impairs autophagic machineries. This possibility remains to be investigated.

Another important finding for this study is that glycogen synthase kinase $3 \beta$ (GSK3 $\beta$ ) is involved in UVB-induced autophagy. GSK3 $\beta$, a serine/threonine protein kinase, which was first described in glycogen metabolism and insulin signaling $(27,28)$, is involved in multiple biological events such as embryonic development, stem cell survival, differentiation, neurodegeneration, tumorigenesis, and cell death $(18,29,30)$. We have previously shown that inhibition of GSK3 $\beta$ promotes the transformation of epidermal cells (10). GSK3 $\beta$ activity is regulated by site-specific phosphorylation. The activity of GSK $3 \beta$ is upregulated by phosphorylation on the $\mathrm{Tyr}^{216}$ residue, and conversely, phosphorylation on $\mathrm{Ser}^{9}$ inhibits GSK3 $\beta$ activity. Phosphorylation of $\operatorname{Ser}^{9}$ is mediated by a number of signaling pathways, such as PI3K/AKT, PKC, MAPK/p90RS, or $\mathrm{mTOR} / \mathrm{p} 70 \mathrm{~S} 6(18,31)$. The mechanism for the regulation of phosphorylation at $\mathrm{Tyr}^{216}$ is less clear. We demonstrate that UVB increases GSK3 $\beta$ phosphorylation at $\operatorname{Ser}^{9}$ but inhibits its phosphorylation at $\mathrm{Tyr}^{216}$, indicating that UVB inhibits GSK $3 \beta$ activity. UVB is shown to activate MAPK, PKC, and PI3K/AKT signaling pathways (32). It is therefore likely that UVB-induced phosphorylation of $\operatorname{Ser}^{9}$ is mediated by one or some of these pathways. Regardless of the mechanisms in which UVB inhibits GSK3 $\beta$, it is likely that UVB activates autophagy through the inhibition of GSK $3 \beta$ because dominantnegative GSK3 $\beta$ enhances UVB-induced autophagy, whereas overexpression of GSK $3 \beta$ inhibits UVB-induced autophagy (Fig. 3). These results suggest that GSK $3 \beta$ negatively regulates autophagy and UVB may affect autophagy by modulating GSK3 $\beta$ activity.

AMP-activated protein kinase (AMPK), a crucial stresssensing enzyme, is activated by a rise in the cellular AMP/ATP ratio. AMPK is an important mediator of autophagy (19). It has been demonstrated that activation of AMPK results in autophagy in human keratinocytes (33). Cadmium-induced activation of AMPK causes autophagy in JB6 cells (34). UV irradiation can regulate AMPK activity. For example, UVB is reported to activate AMPK in murine basal cell carcinoma and skin keratinocytes $(35,36)$. UVC is shown to activate AMPK in pancreatic cancer cells (37). However, Zhang and Bowden (38) suggest that UVB inhibits AMPK in human keratinocytes. We demonstrate here that UVB activates AMPK in JB6 cells, and therefore UVB-mediated autophagy is regulated by AMPK (Fig. 5).
There is considerable interaction between GSK3 $\beta$ and AMPK (39-42). The interaction appears to be two-way; that is, AMPK can affect GSK3 $\beta$ activity and is also regulated by GSK3 $\beta$. In our system, it appears that inhibition of GSK3 $\beta$ results in AMPK activation (Fig. 6). More importantly, inhibition of GSK $3 \beta$ by a dominant-negative GSK3 $\beta$ potentiates UVB-mediated AMPK activation, while overexpression of GSK3 $\beta$ inhibits UVB-induced AMPK activation. This is consistent with the effect of UVB/GSK3 $\beta$ on autophagy and supports a role of AMPK in UVB-mediated autophagy.

UVB causes apoptosis in JB6 cells through complex mechanisms; it may be mediated by oxidative stress, PKC, or a p53-dependent manner $(12,43,44)$. The signaling pathways for UVB-mediated autophagy and apoptosis may or may not overlap. Our study indicates the GSK3 $\beta /$ AMPK pathway contributes to UVB-mediated autophagy. The interaction or cross-talk between the pathways governing autophagy and apoptosis in response to UVB remain to be studied.

\section{Acknowledgements}

This study is supported by grants from the National Institutes of Health (NIH) of the United States (AA017226) and the National Natural Science Foundation of China (NSFC 81071305).

\section{References}

1. Pustisek N and Situm M: UV-radiation, apoptosis and skin. Coll Antropol 35: 239-241, 2011.

2. Matsumura Y and Ananthaswamy HN: Toxic effects of ultraviolet radiation on the skin. Toxicol Appl Pharmacol 195: 298-308, 2004

3. Lippens S, Hoste E, Vandenabeele P, Agostinis $P$ and Declercq W: Cell death in the skin. Apoptosis 14: 549-569, 2009.

4. Alers S, Löffler AS, Wesselborg S and Stork B: The incredible ULKs. Cell Commun Signal 10: 7, 2012.

5. Palumbo $S$ and Comincini S: Autophagy and ionizing radiation in tumors: the 'Survive or not Survive' dilemma. J Cell Physiol: May 14, 2012 (Epub ahead of print).

6. Mizushima N and Komatsu M: Autophagy: renovation of cells and tissues. Cell 147: 728-741, 2011.

7. Chen N and Karantza-Wadsworth V: Role and regulation of autophagy in cancer. Biochim Biophys Acta 1793: 1516-1523, 2009.

8. Martínez-Borra J and López-Larrea C: Autophagy and selfdefense. Adv Exp Med Biol 738: 169-184, 2012.

9. Dong Z, Birrer MJ, Watts RG, Matrisian LM and Colburn NH: Blocking of tumor promoter-induced AP-1 activity inhibits induced transformation in JB6 mouse epidermal cells. Proc Natl Acad Sci USA 91: 609-613, 1994.

10. Ma C, Wang J, Gao Y, Gao TW, Chen G, Bower KA, Odetallah M, Ding M, Ke Z and Luo J: The role of glycogen synthase kinase 3 beta in the transformation of epidermal cells. Cancer Res 67: 7756-7764, 2007.

11. Zhang D, Li J, Gao J and Huang C: c-Jun/AP-1 pathwaymediated cyclin D1 expression participates in low dose arsenite-induced transformation in mouse epidermal JB6 C141 cells. Toxical Appl Pharmacol 235: 18-24, 2009.

12. Won YK, Ong CN and Shen HM: Parthenolide sensitizes ultraviolet (UV)-B-induced apoptosis via protein kinase C-dependent pathways. Carcinogenesis 26: 2149-2156, 2005.

13. Song L, Gao M, Dong W, Hu M, Li J, Shi X, Hao Y, Li Y and Huang C: p85a mediates p53 K370 acetylation by p300 and regulates its promoter-specific transactivity in the cellular UVB response. Oncogene 30: 1360-1371, 2011.

14. Alexander A, Cai SL, Kim J, Nanez A, Sahin M, Maclean KH, Inoki K, Guan KL, Shen J, Person MD, Kusewitt D, Mills GB, Kastan MB and Walker CL: ATM signals to TSC2 in the cytoplasm to regulate mTORC1 in response to ROS. Proc Natl Acad Sci USA 107: 4153-4158, 2010. 
15. Chen G, Ke Z, Xu M, Liao M, Wang X, Frank JA, Bower KA, Shi $\mathrm{X}$ and Luo J: Autophagy is a protective response to ethanol neurotoxicity. Autophagy (In press).

16. Xu M, Bower KA, Wang S, Frank JA, Chen G, Ding M, Wang S, Shi X, Ke Z and Luo J: Cyanidin-3-glucoside inhibits ethanolinduced invasion of breast cancer cells overexpressing ErbB2. Mol Cancer 9: 285, 2010

17. Barth S, Glick D and Macleod KF: Autophagy: assays and artifacts. J Pathol 221: 117-124, 2010.

18. Luo J: Glycogen synthase kinase 3beta (GSK3beta) in tumorigenesis and cancer chemotherapy. Cancer Lett 273: 194-200, 2009.

19. Mihaylova MM and Shaw RJ: The AMPK signaling pathway coordinates cell growth, autophagy and metabolism. Nat Cell Biol 13: 1016-1023, 2011.

20. Ehrhart JC, Gosselet FP, Culerrier RM and Sarasin A: UVB-induced mutations in human key gatekeeper genes governing signalling pathways and consequences for skin tumourigenesis. Photochem Photobiol Sci 2: 825-834, 2003.

21. Xu Y, Shao Y, Zhou J, Voorhees JJ and Fisher GJ: Ultraviolet irradiation-induces epidermal growth factor receptor (EGFR) nuclear translocation in human keratinocytes. J Cell Biochem 107: 873-880, 2009.

22. Huang C, Ma WY and Dong Z: The extracellular-signalregulated protein kinases (Erks) are required for UV-induced AP-1 activation in JB6 cells. Oncogene 18: 2828-2835, 1999.

23. Won YK, Ong CN, Shi X and Shen HM: Chemopreventive activity of parthenolide against UVB-induced skin cancer and its mechanisms. Carcinogenesis 25: 1449-1458, 2004.

24. Roy S, Deep G, Agarwal C and Agarwal R: Silibinin prevents ultraviolet B radiation-induced epidermal damages in JB6 cells and mouse skin in a p53-GADD45alpha-dependent manner. Carcinogenesis 33: 629-636, 2012.

25. Rodriguez-Rocha H, Garcia-Garcia A, Panayiotidis MI and Franco R: DNA damage and autophagy. Mutat Res 711: 158-166, 2011.

26. Chen LH, Chu PM, Lee YJ, Tu PH, Chi CW, Lee HC and Chiou SH: Targeting protective autophagy exacerbates UV-triggered apoptotic cell death. Int J Mol Sci 13: 1209-1224, 2012.

27. Ougolkov AV and Billadeau DD: Targeting GSK-3: a promising approach for cancer therapy? Future Oncol 2: 91-100, 2006.

28. Forde JE and Dale TC: Glycogen synthase kinase 3: a key regulator of cellular fate. Cell Mol Life Sci 64: 1930-1944, 2007.

29. Kim JW, Lee JE, Kim MJ, Cho EG, Cho SG and Choi EJ Glycogen synthase kinase 3 beta is a natural activator of mitogen-activated protein kinase/extracellular signal-regulated kinase kinase kinase1(MEKK1). J Biol Chem 278: 13995-14001, 2003.

30. Luo J: GSK3beta in ethanol neurotoxcity. Mol Neurobiol 40: 108-121, 2009.

31. Ding Q, He X, Xia W, Hsu JM, Chen CT, Li LY, Lee DF, Yang JY, Xie X, Liu JC and Hung MC: Myeloid cell leukemia-1 inversely correlates with glycogen synthase kinase-3beta activity and associates with poor prognosis in human breast cancer. Cancer Res 67: 4564-4571, 2007.
32. Nomura M, Kaji A, Ma WY, Zhong S, Liu G, Bowden GT, Miyamoto KI and Dong Z: Mitogen- and stress-activated protein kinase 1 mediates activation of Akt by ultraviolet B irradiation. J Biol Chem 276: 25558-25567, 2001.

33. Tong X, Smith KA and Pelling JC: Apigenin, a chemopreventive bioflavonoid, induces AMP-activated protein kinase activation in human keratinocytes. Mol Carcinog 51: 268-279, 2012.

34. Son YO, Wang X, Hitron JA, Zhang Z, Cheng S, Budhraja A, Ding S, Lee JC and Shi X: Cadmium induces autophagy through ROS-dependent activation of the LKB1-AMPK signaling in skin epidermal cells. Toxical Appl Pharmacol 255: 287-296, 2011.

35. Byekova YA, Herrmann JL, Xu J, Elmets CA and Athar M: Liver kinase B1 (LKB1) in thepathogenesis of UVB-induced murine basal cell carcinoma. Arch Biochem Biophys 508: 204-211, 2011.

36. Cao C, Lu S, Kivlin R, Wallin B, Card E, Bagdasarian A, Tamakloe T, Wang WJ, Song X, Chu WM, Kouttab N, Xu A and Wan Y: SIRT1 confers protection against UVB-and $\mathrm{H} 2 \mathrm{O} 2-$ induced cell death via modulation of p53 and JNK in cultured skin keratinocytes. J Cell Mol Med 13: 3632-3643, 2009.

37. Adachi S, Yasuda I, Kawaquchi J, Yamauchi T, Nakashima M, Itani M, Nakamura M, Yoshioka T, Moriwaki $\mathrm{H}$ and Kozawa $\mathrm{O}$ : Ultraviolet enhances the sensitivity of pancreatic cancer cells to gemcitabine by activation of 5'AMP-activated protein kinase. Biochem Biophys Res Commun 414: 53-59, 2011.

38. Zhang $\mathbf{J}$ and Bowden GT: UVB irradiation regulates Cox-2 mRNA stability through AMPK and HuR in human keratinocytes. Mol Carcinog 47: 974-983, 2008.

39. Shin SM, Cho IJ and Kim SG: Resveratrol protects mitochondria against oxidative stress through AMP-activated protein kinase-mediated glycogen synthase kinase-3beta inhibition downstream of poly (ADP-ribose) polymerase-LKB1 pathway. Mol Pharmacol 76: 884-895, 2009.

40. de Candia P, Minopoli G, Verga V, Gargiulo A, Vanoni M and Alberghina L: Nutritional limitation sensitizes mammalian cells to GSK-3 $\beta$ inhibitors and leads to growth impairment. Am J Pathol 178: 1814-1823, 2011.

41. Yuan HD and Piao GC: An active part of Artemisia sacrorum Ledeb. Suppresses gluconeogenesis through AMPK mediated GSK3 $\beta$ and CREB phosphorylation in human HepG2 cells. Biosci Biotechnol Biochem 75: 1079-1084, 2011.

42. Yuan HD, Kim do Y, Quan HY, Kim SJ, Jung MS and Chung SH: Ginsenoside $\operatorname{Rg} 2$ induces orphan nuclear receptor SHP gene expression and inactivates GSK3 $\beta$ via AMP-activated protein kinase to inhibit hepatic glucose production in HepG2 cells. Chem Biol Interact 195: 35-42, 2012.

43. Chen N, Ma W, Huang C and Dong Z: Translocation of protein kinase Cepsilon and protein kinase Cdelta to membrane is required for ultraviolet $\mathrm{B}$-induced activation of mitogenactivated protein kinases and apoptosis. J Biol Chem 274: 15389-15394, 1999.

44. Yang S, Misner BJ, Chiu RJ and Meyskens FL Jr: Redox effector factor-1, combined with reactive oxygen species, plays an important role in the transformation of JB6 cell. Carcinogenesis 28: 2382-2390, 2007. 